\title{
Drug Suspects Perception of Factors Responsible For Illicit Drug Trade in Cross River State, Nigeria
}

\author{
Okpa, J. T. \& Ukwayi, J. K. \\ Department of Sociology, University of Calabar, Calabar, Nigeria
}

\begin{abstract}
The essence of this study is to determine factors responsible for illicit drug trade in Cross River State, Nigeria. The specific objectives of the study are, to examine the relationship between inadequate manufacturing industry, economic recession, and illicit drug trade in Cross River State. The study adopted survey research design. The design was opted for because it enabled the researcher to get accurate and correct information from the respondents through the administration of questionnaire. Purposive sampling technique was used in selecting one hundred and twenty seven (127) detainee (suspects) from National Drug Law Enforcement Agency (NDLEA) Cross River state command. Data were collected from both primary and secondary sources. Elucidated data were statistically analyzed using linear regression to estimate the tested variables. All hypotheses were tested at 0.05 level of significance with 2 degrees of freedom. The result of the analysis shows that a significant relationship exists between inadequate manufacturing industry, economic recession, and illicit drug trade in Cross River state, Nigeria. Based on the findings of this study the following recommendations were made; Government at all levels should endeavour to create conducive atmosphere for industrialist to grow their business. This can be achieve by providing affordable loans with little or no interest, tax holiday, regular and steady power supply, efficient transportation system, ready-made market and other incentives. These will boost production capacities of the available industries and generate employment for job seekers
\end{abstract}

Keywords: drug suspects perception, illicit drug, trafficking, economic recession, and inadequate manufacturing industry

\section{INTRODUCTION}

Nigeria, like many other developed and developing countries of the world is faced with the problem of illicit drug trade. Illicit drug trade is a flourishing outlaw economic activity prevalent in most state across Nigeria. This economic activity, which involves the production, circulation, and use of banned substances such as cocaine, heroin, and Indian hemp, has attracted global concern over the years (Ellis, 2009; Shehu, 2009; UNODC World Drug Report, 2010; Maqbool, 2014). According to USAID report (2013), illicit drug trade, like any other type of transnational organized crime, threatens political and socio-economic development, foster corruption, and violence, undermine rule of law and good governance, jeopardize economic growth, and pose potential public health risks. NDCMP (2015-2019) report revealed that over the years, Nigeria has emerged as one of the major drug trafficking hub in the world. Similarly, the United States Drug Enforcement Agency (DEA) report revealed that Nigeria is one of those countries in West Africa sub-region that is becoming the key command and control point for Spanish and Italian drug trafficking groups (UNODC, 2010). The UN World Drug Report 2016, shows that while drug production, trafficking, and consumption have remained a global challenge, the trade have increased dramatically in some West Africa countries like Nigeria. Nigeria has become a global hub for illegal drugs transiting from both Latin America and Asia to end users in North America, Europe, the Middle East, and Asia (Lafiaji, 2004; Dambazau, 2007).

The problem of illicit drug trade is a social evil that is assuming different and dangerous dimension, with its attendant consequences on the safety of lives and properties across the country (Iwarimie-Jaja, 2012, Felix \& Ukwayi, 2014). The type of illicit substances trafficked has expanded from cocaine and heroin to amphetamine-type stimulants (Dambazau, 2007). Nigeria is particularly susceptible to the influence of transnational criminal organizations because of widespread corruption, poverty, illiteracy, greed, laziness, and desire to get rich quick. Other factors include; porous border, strategic geographic location, and mismanagement, lack of political will, ineffective law enforcement agencies, and inadequate financial aid to security agencies (Felix \& Ukwayi, 2014, Adeniyi, 2016).

In the same, Adeniyi (2004) and UNODC (2008) Felix \& Ukwayi (2014) noted that weak criminal justice system, economic downturn, inadequate manufacturing industry, and unemployment that characterize many states in the country provide a conducive atmosphere for illicit drug trade to strive. They observed that drug barons and other criminal network organizations take advantage of the vulnerability of some members of 
the society to co-opt them into illicit drug trade. There is no gainsaying that illicit drug trade affects socioeconomic and sustainable development in Nigeria. Although determining the precise figures of the volume and profits from drug trafficking is difficult, the United Nations Office on Drugs and Crime (UNODC) 2010 estimates that West African criminal networks could have earned between $\$ 1.8$ and $\$ 2.8$ billion in cocaine sales in 2009. The high profits from this trade, particularly cocaine and heroin is use to fund armed groups, and distorts legitimate markets. The drug use that eventually accompanies the trade can lead to increased violence, the erosion of social capital, and the breakdown of families and communities values. Despite the prevailing problems of illicit drug trade in Nigeria and specifically in Cross River State, largely missing in literature is the study focused on identifying economic factors responsible for the illicit trade. This study attempts to bridge this gap by identifying factors responsible for illicit drug trade in Cross River state, Nigeria.

\section{Objectives of the study}

The major objective of the study is to determine factors responsible for illicit drug trade in Cross River State, Nigeria. Specifically, the study is designed to:

(i) examine the relationship between economic recession and illicit drug trade in Cross River State

(ii) assess the relationship between inadequate manufacturing sector and illicit drug trade in Cross River State

\section{Research questions}

The following research question were raised to guide this study

(i) What is the relationship between economic recession and illicit drug trade in Cross River State

(iii) How does inadequate manufacturing sector lead to illicit drug trade in Cross River State.

\section{Statement of hypotheses}

The following null hypotheses were formulated to provide direction to the study:

(i) Economic recession does not significantly lead to illicit drug trade in Cross River State.

(ii) Inadequate manufacturing sector does not significantly lead to illicit drug trade in Cross River State.

\section{Significance of the study}

In the area of research, the study will establish the link between economic recession, inadequate manufacturing sector and illicit drug trade. It will be of interest to researchers because it will serve as a background work for them to anchor their future studies. It will guide them on the areas that have been covered and the areas in which more work should be carried out. The data generated will serve as a guide for further investigations. The study will serve as eye opener to the government on the causes of illicit drug trade so as to be able to fashion out relevant programmes to address this menace. It will also draw the attention of government to unemployment situation and its propelling force on illicit drug trade, so as to vigorously embark on job creation ventures and provides job opportunities to the unemployed persons in the country. This study will avail non researchers the opportunity to understand the risk factors associated with illicit drug trade and its impact on the socio-economic well-being and development of the society. It will further expose them to the prevailing influence of inadequate manufacturing sector on illicit drug trade. This study is very important and useful to policy makers. It serves as wakeup call to them. It is expected that the study will provide data on the nature and extent and prevalence of illicit drug trade in Nigeria. This will serve as a guide in formulating drug control policies and determining appropriate prevention, intervention and counter narcotics measures.

\section{Scope of the study}

The study was limited to factors responsible for illicit drug trade in Cross River State, Nigeria. The study specifically examine factors such as economic recession, inadequate manufacturing sector and the dependent variable illicit drug trade. The study was carried out in NDLEA Cross River state command.

\section{Economic recession and illicit drug trade}

\section{REVIEW OF RELATED LITERATURE}

According, to National Bureau on Economic Research (NBER), recession refers to a period where there is a pronounced demur in economic activity spread across the economy, which duration is exceeds some months, as a result of that affects the real GDP, income generation, job creation, production activities, and distribution. Recession generally refers to a session when the economy is in a disjointed form. This period is characterised with increase in the prices of goods and services, retrenchment, lost of jobs, suffering, pains, and increase in criminal activities. When economy is not growing, jobs are not created rather it is unemployment that is inadvertently created. According to a UNODC report monitoring the impact of economic crises on crime, the report revealed that Crime increases during economic crises. It was observed that during the period of economic stress the incidence of robbery doubles, and other forms of crime also increased (UNODC, 2010). 
Osojood and chambers (2000) assert that previous studies on the links between economic crisis and criminal behaviour reveal only a moderate positive link between economic recessions and crime. Schmitt and Warner (2011) stated that the nexus between recession and crimes has been found to be contingent upon factors such as rates of inflation and the magnitude of the obstacles posed to criminal activity through the use of incarceration and the relative size or more effective reach of law enforcement

The argument has been that current economic condition in the country occasioned by poor management of the economy coupled with global economic meltdown has contributed to the upsurge in illicit drug trade in Nigeria. This prevailing economic situation makes it difficult for some Nigerians to survive in the midst of economic hardship. As a result of their inability to survive the struggle, some Nigerians have resorted to illicit drug trade to eke out a living. Besides there is a lot of unemployment and jobs lost occasioned by economic recession in the country, this has compounded the problem of created by recession. According to Fobur (2009) in a situation of economic recession, impatient Nigerians look beyond the frontiers of their nation for quick money spinning business no matter how obnoxious. He reasoned that drug trade is the commonest of such obnoxious business. He argued further that, the reaction of some Nigerians to the present economic hard times is by taking to the life of crime, particularly illicit drug trade; since it involves the priceless foreign currencies of either the US dollars or pound sterling especially with the failure of Naira (Fobur, 2009). Nowadays, drug barons, traffickers, and couriers are enticed by European Euro currency, which is more powerful than US dollars, considering the dwindling value of Nigeria Naira against these foreign currencies.

\section{Inadequate manufacturing sector and illicit drug trade}

As a country in sub-Saharan Africa, Nigeria is blessed with enormous business and investment potentials, the presence of copious, pulsating, and energetic human and natural resources within the country makes the nation extra-ordinarily blessed. This sounds interesting, but sad enough, the country has constantly witness social, economic, and political crisis which have retard her growth and development over the years (Okoye, 1999). This has been blamed on the inadequate manufacturing sector which have created increased rate of unemployment in the country. However, scholars have attributed the cause of high rate of unemployment in Nigeria to inadequate vibrant manufacturing industry. Bello (2003) posits that Nigeria lacks vibrant manufacturing sector which has the capacity to absorb unemployed youths in Nigeria, as there are over 800 collapsed industry in the country and over 37 factories have closed shops in 2009. About half of the remaining operating firms have been classified as "ailing," a situation that poses a great threat to the survival of manufacturing in the country in the next few years.

A survey by Manufacturers Association of Nigeria (MAN) (2010) revealed that 834 firm shut down their operations in 2009 across the country. The study which usually covers five manufacturing enclaves, into which the country is divided, in terms of manufacturing activities have Lagos, north, southeast, south-south and southwest region.. The report of the survey showed that in 2009, a total number of 176 firms became terminally sick and collapsed in the northern area, comprising the Kano and Kaduna states manufacturing axis. In the southeast area, which is comprised of Anambra, Enugu, Ebonyi, Imo, and Abia states, a total number of 178 companies closed during the period. While in the south-south area, which consisted of Rivers, Cross River, Delta, Edo, Bayelsa and Akwa Ibom states, 46 companies shut down operations before December 2009. According to the survey, the southwest area, which is comprised of Oyo, Ogun, Osun, Ondo, Ekiti, Kogi, and Kwara states, lost 225 companies during the year. It said that the Lagos area, covering Ikeja, Apapa, Ikorodu, and other industrial divisions in the state, followed closely with 214 manufacturing firms closing shop before the end of 2009 (Okafor, 2011; Oviawe, 2010; 2011; Idoko, 2013).

The un-conducive economic conditions in Nigeria, namely lack of electricity, poor road network, poor communication system, insecurity, among others have caused the close down of many companies, throwing many people into labour market. In a certain year over 100 textile factories closed shops across the country and the trend continues (Adawo; Essien \& Ekpo, 2012). Factories depend on generators to power their factories and this is inefficient and increases unit cost of production making their products uncompetitive. Yet the country becomes a dumping ground for all manners of imports. Besides, high and multiple levies and taxations being paid by these companies, energy crises have combined to make the cost of doing business in Nigeria to be very exorbitant. When the industry and factories closed shops or relocated to a friendlier economic environment, workers are laid off and prospects of recruiting new ones dashed. All these exacerbated the crisis of unemployment in the labour market (Gadzama, 2010; Onifade, 2011).

\section{Theoretical consideration}

\section{The Blocked Opportunity Theory}

The blocked opportunity also known as differential opportunity theory is associated with Richard Cloward and Lylod Ohlin (1961). The basic tenets of this theory concur with Merton postulations that in every human society there is unequal access to conventional and approved means to achieve legitimate goals. The 
blocked opportunity theory also noted that access to illegal means is not evenly available and not equally distributed in the social system. The theory by implication argues that not every individual can achieve their goals or aspirations through legal means. The reason is that individuals do not have equal access to material possessions, since there are differences in the opportunities available to individuals who adopt legitimate means to achieve their culturally approved goals (Ugwuoke, 2010). In the same vein, not all individuals who suffer strain as a result of blocked opportunities are able to use illegitimate means since these are also not equally available and distributed in the society. Cloward and Ohlin (1960) went further to argue that crime results from the frustration of poor youths whose aspirations for success are blocked in a middle class society where there is a disjunction between the cultural expected goals and the means available for their attainment (Igbo, 2007) Therefore they provided three distinct types of deviant sub-cultures for achieving goals. These are criminal, conflict and the retreatist sub-cultures. In their explanation, the criminal sub-culture refers to the successful criminal who teaches the juveniles the opportunities to engage in criminal acts that makes them delinquent. The emphasis in this sub-culture is that crime brings monetary benefits; such crimes include theft, armed robbery, fraud and drug trafficking. The conflict sub-cultures has the objectives of achieving status through force or intimidation. Here, if none of the legitimate or illegitimate means are available to make money the delinquent often become frustrated and dissatisfied and form violent gangs to vent their anger. The retreatist sub-culture: As a result of their failure to succeed through neither legitimate nor illegitimate adaptation, the individual here usually turns to illegal drug use and alcohol consumption as a way to escape from life difficulties. This theory was adopted because of its relevant to this study. In most cases, unemployed persons that are frustrated, dejected and unhappy look for illegal means to achieve their goals and aspirations. Since people cherish money, power, prestige and status they would venture into criminal activities that can give them good money. Illicit drug trade, being a multi-million naira business relatively becomes attractive to the gullible youths and unemployed persons. Therefore, if the unemployed persons see that their opportunity to get work and earn a living has been blocked, they become frustrated and may be compelled to seek for illegitimate means to achieve their ambition and thereby resort to drug trafficking.

\section{METHODOLOGY}

Survey research design was adopted because the design allows for the selection of samples and the generalization of research findings (Ndiyo, 2005). The population of the study consists of males and females drug suspects arrested for alleged engagement in the distribution, transportation, sale, dealing, peddling, possession and cultivation of narcotic drugs and psychotropic substances in Cross River State, Nigeria. In view of the small number of the population, the total population of the study was used as the sample for this study. Thus, a total of one hundred and twenty-seven (127) suspects in NDLEA custody in Cross River State Command constitutes the sample of the study. The sampling technique adopted in this study is the purposive sampling technique. This was used because the respondents (suspects) have been identified where they are located and confined in NDLEA custody. This makes it convenient for the researcher to reach them and study them in their pre-trial detention facilities. The instrument used for data collection is a questionnaire. Each Item in the questionnaire requires the respondents to indicate the frequency under strongly agree (SA), Agree (A), Disagree (D), Strongly Disagree (SD). The questionnaire was subjected to face and content validity. This was achieved by giving the instrument to experts in Educational Test and Measurement for their criticism and thorough Scrutiny, in terms of relevance, difficulty levels and appropriateness of words, and representativeness of the items to content area. Linear regression was adopted in the analysis of the coded responses from the respondents.

\section{RESEARCH FINDINGS}

Table 1 explains respondent's demographic information. The distribution of respondents in respect to gender reveals that majority of the suspects 79.5 per cent $(\mathrm{N}=101)$ are male while only 20.5 per cent $(\mathrm{N}=26)$ are female. This suggests that males are more involved in drug trafficking because they are physically aggressive, more physically active, more logical and often have good special skills. Also, the frequent pressure on men to provide for their family as "breadwinner", "family provider" in the absence of a job has increased the number of men that engaged in drug trafficking. The spread of respondents in terms of age shows that 20.5 per cent $(\mathrm{N}=26)$ of drug suspects are below 25 years, 30.7 per cent $(\mathrm{N}=39)$ are between the ages of 26-35 years, 26.0 per cent $(\mathrm{N}=33)$ are between the ages of 36-45 years, 15.7 per cent $(\mathrm{N}=20)$ are between the ages of 46-55 years while only 7.1 per cent $(\mathrm{N}=9)$ are above 56 years, all the age groups are represented since age is not a barrier to commit crime. However, respondents within active working age group ( $26-55$ years) constitute the majority and dominate the illicit drug trafficking. This could be attributed to the fact that Nigeria population largely consists of young people and lack of employment opportunities experienced in the country might tempt them to commit drug crime to get rich quick. Respondents' responses to marital status reveal that majority 46.5 per cent $(\mathrm{N}=59)$ are single, 40.2 per cent $(\mathrm{N}=51)$ are married; while 13.4 per cent $(\mathrm{N}=17)$ are divorced or 
separated. This can be ascribed to the inordinate ambitions of young people to become wealthy overnight and rival with older people. However, it shows that both the singles and married are actively involved in illicit drug commerce. In terms of occupation disposition of the respondents, the majority of the suspects claimed to be selfemployed 33.1 per cent (42), 28.3 per cent (36) are unemployed, 19.7 per cent (25) are traders, 11.0 per cent (14) are farmers, 7.9 per cent are others which include fishermen, private workers, artisans, students and so on. The self-employed whose income is too low to guarantee them a better standard of living are more involved in illicit drug enterprise. Most of them admitted that their trading business is not giving them enough money to meet their responsibilities. This is followed by the unemployed who are jobless or applicants that are easily lured into drug trafficking. They admitted that due to lack of job opportunities, they are compelled to deal in illicit drugs to earn a living. The involvement of respondents of other occupational categories in illicit drug commerce can be ascribed to low-income brought about by low educational qualifications, general meltdown in the economy and underemployment, which serve as driving force to engage in illicit drug trade. The distribution of respondents in respect to religious affiliation reveals that majority 61.4 per cent $(\mathrm{N}=78)$ practice Christianity; the group with the least representation are Islam faithful with 14.2 per cent $(\mathrm{N}=18)$; African Tradition Religion faithfuls are represented with 24.4 per cent $(\mathrm{N}=31)$. More of the respondents are Christians because the study is carried out in the state where Christianity is the dominant religion. The compartmentalisation of respondents in terms of educational qualification shows that 15.0 per cent $(\mathrm{N}=19)$ have no formal education, 22.8 per cent of the respondents $(\mathrm{N}=29)$ have completed their primary education, majority of the respondent 30.7 per cent $(\mathrm{N}=39)$ have completed their secondary education, 18.9 per cent $(\mathrm{N}=$ 24) have completed their NCE/OND education while the least groups are respondents with HND/ B.Sc. certificate and others with a representation of 6.3 per cent $(\mathrm{N}=8)$ and 6.3 per cent $(\mathrm{N}=8)$ respectively. This distribution shows that majority of the drug suspects ( 68.5 per cent) have either no formal education, or low (primary and secondary) educational attainment. This category of people may be desperate to get rich quick and this might be responsible for their involvement in illicit drug trade. Those with higher educational qualifications have self esteem, self value and worth with the hope that their educational attainment will guarantee them better jobs. This has the capacity to discourage them from taking the risk of trafficking in dangerous drugs and thereby avoid the embarrassment of being arrested and convicted for illicit drug trade. Furthermore, information on drugs frequently trafficked in the command showed that cannabis was the most frequently trafficked drug, with a representation of 44.9 per cent $(\mathrm{N}=57)$. Cocaine is second with 17.3 per cent $(\mathrm{N}=22)$, next is combined with a representation of 13.4 per cent $(\mathrm{N}=17)$ followed by heroine with a representation of 11.0 per cent $(\mathrm{N}=14)$, depressant has a representation of 8.7 per cent $(\mathrm{N}=11)$ and the least represented group are other forms of drugs with a representation of 4.7 per cent $(\mathrm{N}=6)$. It is a fact that cannabis is cultivated illegally in different parts of the country and this makes the drug to be the most trafficked drug in the state and indeed Nigeria. This is because of the suitable soil and climate condition, which favour its cultivation and growth. The distribution of respondents in respect to predisposing factors reveal that, majority of the drug suspects 49.6 per cent $(\mathrm{N}=63)$ engage in drug trafficking as a result of unemployment, next is the get-rich-quick syndrome with a representation of 22.8 per cent $(\mathrm{N}=29)$, followed by peer group influence with a representation of 15.0 per cent $(\mathrm{N}=19)$, ignorance is represented with 10.2 per cent $(\mathrm{N}=13)$ and other factors which ranked the least with a representation of 2.4 per cent $(\mathrm{N}=3)$. Respondents responses to mode of drug concealment indicate that majority 55.1 per cent $(\mathrm{N}=70)$ conceal illicit drugs through means not highlighted in the questionnaire such as jerry cans, drums, plastic containers, bags, roofs, tins nylons among others. 23.6 per cent $(\mathrm{N}=30)$ conceal drugs in sacks while only 21.3 per cent $(\mathrm{N}=27)$ conceal drugs in their pockets. The information there in, are facts gathered from the fieldwork by the researcher at the Cross River State NDLEA command.

\section{Hypothesis one}

Hypothesis one in the null form states that, economic recession is not significantly lead to illicit drug trade in Cross River State. The independent variable (predictor) in the hypothesis is economic recession, while the dependent variable is drug trafficking. To test the hypothesis, simple linear regression was used to analyse the data of the sub-scale on the variable. Result of the analysis is presented in table 2 . The result of the analysis presented in Table 2 reveals that there is a significant predictive relation between economic recession and illicit drug trade. The calculated F-ratio $18.253(\mathrm{p}<.05)$ is greater than the critical F-ratio of 3.84 which is obtained at .05 level of significant under the degrees of freedom 1 and 125 . The obtained significant value of .00 was seen to be less than .05 significant level used in the study. With this result, the null hypothesis which states that economic recession is not significantly lead to illicit drug trade in Cross River State was rejected. Thus, there was a significant contribution of the independent variable to the prediction of illicit drug trade. The $\mathrm{R}$ which showed correlation coefficient of the independent variable with the dependent variable is seen to be .36 which showed a positive correlation between the variables. The coefficient of determination $\left(\mathrm{R}^{2}\right)$ is seen to be .13 , this showed that up to 13 per cent of the variance in illicit drug trade is explained by the independent variable. The regression coefficient indicated the degree of the contribution of the independent variable to the variation in the 
dependent variable. It was seen that at .05 level of significance the predictor (explanatory) variable was found to be significant. The standardized coefficient and $\mathrm{t}$-value showed the effect of the independent variable. With $\mathrm{t}$ value of $4.27(\mathrm{p}<.05)$ and Beta of .36 indicates that the independent variable has $36 \%$ variation to the dependent variable. Therefore, there was a significant relative relationship between economic recession and illicit drug trade among arrested drug suspects in Cross River NDLEA command.

TABLE 1: Linear regression analysis of economic recession as a predictor of illicit drug trade

\begin{tabular}{|c|c|c|c|c|c|}
\hline Source of variation & SS & df & MS & $\mathrm{F}$ & Sig. \\
\hline Regression & 117.537 & 1 & 117.537 & 18.253 & $000 * *$ \\
\hline Residual & 804.904 & 125 & 6.439 & & \\
\hline \multirow[t]{3}{*}{ Total } & 922.441 & 126 & & & \\
\hline & \multicolumn{5}{|c|}{ Unstandardized Standardized } \\
\hline & Coefficient B & \multicolumn{2}{|c|}{ STD error coefficient Beta } & $\mathrm{t}$ & sig \\
\hline (constant) & \multirow[t]{2}{*}{9.490} & \multicolumn{2}{|l|}{1.462} & 6.42 & $.000 * *$ \\
\hline \multicolumn{5}{|l|}{ Economic } & \\
\hline Recession & .437 & .102 & & .357 & 4.272 \\
\hline
\end{tabular}

Dependent variable: illicit drug trade

$\mathrm{R} \quad .357^{\mathrm{a}}$

R square $\quad .127$

Standard error of estimate $\quad 2.538$

**significant at 0.05 level, $\mathrm{df}=1,125 ; \quad$ critical $\mathrm{F}=3.84$

\section{Hypothesis two}

Hypothesis two in the null form states that, inadequate manufacturing sector does not lead to illicit drug trade in Cross River State. The independent variables (predictor) is inadequate vibrant manufacturing sectors while dependent variable is illicit drug trade. Statistical technique used for analysis of data on this sub-scale is linear regression. Result of the analysis is presented in table 3. The result of the analysis presented in Table 3 reveals that there is a significant predictive relation between inadequate manufacturing sectors and illicit drug trade. The calculated F-ratio $73.007(\mathrm{p}<.05)$ is greater than the critical F-ratio of 3.84 which is obtained at .05 level of significant under the degrees of freedom 1 and 125. The obtained significant value of .00 was seen to be less than .05 significant level used in the study. With this result, the null hypothesis which states that, inadequate manufacturing sectors does lead to illicit drug trade in Cross River State was rejected. Thus, there was a significant contribution of the independent variable (inadequate manufacturing sector) to the prediction of illicit drug trade. The $\mathrm{R}$ which showed correlation coefficient of the independent variable with the dependent variable is seen to be .61 which showed a positive correlation between the variables. The coefficient of determination $\left(\mathrm{R}^{2}\right)$ is seen to be .36 , this showed that up to 36 per cent of the variance in illicit drug trade is explained by the independent variable. The regression coefficient indicated the degree of the contribution of the independent variable to the variation in the dependent variable. It was seen that at .05 level of significance the predictor (explanatory) variable was found to be significant. The standardized coefficient and t-value showed the effect of the independent variable. With t-value of $8.54(\mathrm{p}<.05)$ and Beta of .61 indicates that the independent variable has $61 \%$ variation to the dependent variable. Therefore, there was a significant positive relationship between inadequate manufacturing sector to illicit drug trade in Cross River state, Nigeria.

TABLE 2: Linear regression analysis of inadequate manufacturing sector as a predictor of illicit drug trade

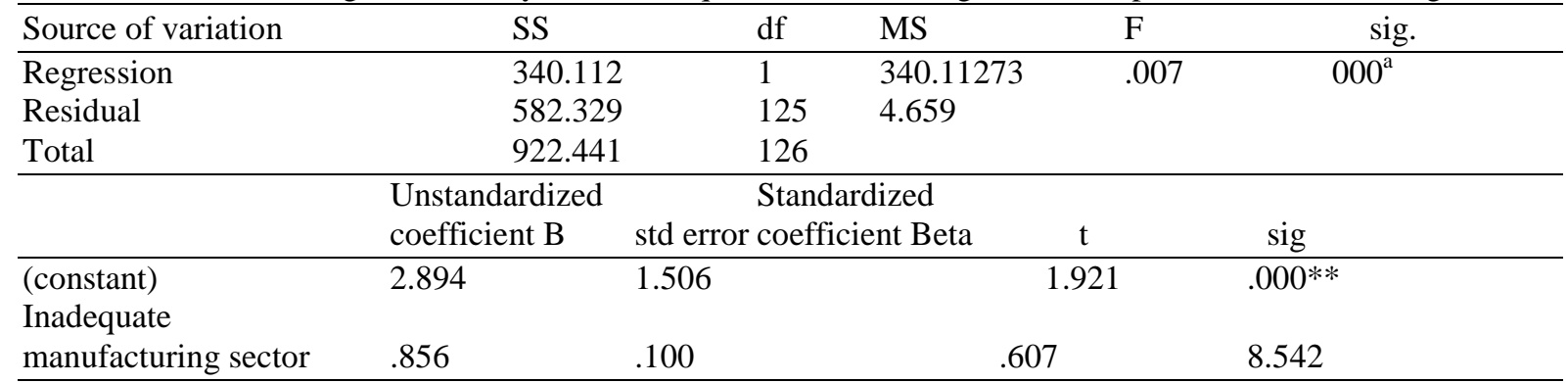

Dependent variable: illicit drug trade

R $\quad .607^{\mathrm{a}}$

R square $\quad .364$

Standard error of estimate $\quad 2.158$

**significant at 0.05 level, $\mathrm{df}=1,125 ; \quad$ critical $\mathrm{F}=3.84$ 


\section{DISCUSSION OF FINDINGS \\ Economic recession and illicit drug trade}

From the result of hypothesis one, the study showed a significant relationship between economic recession and illicit drug trade in Cross River State, Nigeria. The study revealed that economic recession is characterised by hardship which compel the unemployed to venture into trading of hard drugs for survival. This finding is in accordance with the works of Osgood and Chambers (2000), Fobur (2009), Schmitt and Warner (2011). They all observe that economic recession promotes drug trafficking and other related crimes. The present economic realities occasioned by mismanagement of the nation's wealth by the political elites coupled with global economic crisis have led poor, unemployed and other group of individuals into the production, distribution of illicit drugs across the country. The prevailing economic situation has made life difficult for most Cross Riverians who have resorted to trafficking of illicit drugs for survival. The finding agrees with Osgood and Chambers (2000) who noted that, in the absence of a steady, legitimate income, people resort to crime. They also observed that the unemployed have more time than workers to engage in criminal activities. Similarly, Fobur (2009) posits that during economic recession, impatient Nigerians residing in Cross River sate look beyond the frontiers of their nation for quick money spinning business no matter how obnoxious. He reasoned that drug trade is the commonest of such obnoxious business. He argued further that, the reaction of some Nigerians to the present economic hard times is by taking to the life of crime, particularly drug trafficking; since it involves the priceless foreign currencies of either the US dollars or pound sterling especially with the failure of naira.

\section{Inadequate manufacturing sector and illicit drug trade}

The study also reveals that inadequate manufacturing industry has contributed to the problem of illicit drug trafficking among the unemployed in the Cross River State, Nigeria. The findings of the study indicates that the inability of available manufacturing industry to absorb the teaming job seekers has led some of them into illicit drug trade. This finding agree with Bello (2003), Gadzama (2010), Onifade (2011), Adawo, Essien and Ekpo (2012), they all attributed the cause of high rate of unemployment in Nigeria to inadequate vibrant manufacturing industry. This suggests that, the absence of adequate manufacturing industry compel the jobless into trafficking in illicit drugs as a means of survival. Research findings on the relationship between inadequate manufacturing sector and illicit drug trade are still scantily available. This might be attributed to the fact that researchers have not directed much attention in this area. However, it is not conclusive to compare this present study with those earlier cited in the literature. This is because earlier studies did not examined inadequate manufacturing sector and illicit drug trade.

\section{CONCLUSION AND RECOMMENDATIONS}

This study examined factors responsible for illicit drug trade in Cross River State, Nigeria. Emphasis was on the relationship between economic recession, inadequate manufacturing industry and illicit drug trade. After extensive statistical analysis of each of the formulated hypotheses which was tested at 0.5 level of significance, the following conclusions were arrived at:

(i) There is a significant relationship between economic recession and illicit drug trade. It was established in this study that hardship during the period of economic recession compels the jobless to engage in illicit drug trade. Also inability of job seekers to meet their needs during economic recession pushes them into trafficking in hard drugs to eke out a living.

(ii) There is a relationship between inadequate manufacturing sector and illicit drug trade. Inadequate manufacturing industry and the inability of the existing ones to absorb the army of job seekers is linked to why they engage in illicit drug trade.

The following recommendations was put forward for this study

(i) Beyond self-help offered by good spirited individuals, poverty alleviation programmes by government should be strengthen and enhanced to carter for the needs of indigent and vulnerable individuals in the society. This will discourage them from engaging in illicit drug trade especially during the period of economic recession.

(ii) Government at all levels should endeavour to create conducive atmosphere for industrialist to grow their business. This can be achieve by providing affordable loans with little or no interest, tax holiday, regular and steady power supply, efficient transportation system, ready-made market and other incentives. These will boost production capacities of industry and generate employment for job seekers

(iii) Government should adopt several measures to boost the economy and make it buoyant for different economic activities to boom and provide employment opportunities for teeming Nigerian youths so as to discourage them from engaging in illicit drug enterprise. 


\section{REFERENCES}

[1]. Adawo, M. A.; Essien, E. B. \& Ekpo, N. U. (2012). Is Nigeria's unemployment problem unsolvable? Current Research Journal of Social Sciences, 4(6), 389-395.

[2]. Adeniyi, K. E. (2000). The role of the National Drug Law Enforcement Agency in combating drug problem in Nigeria Tertiary Institutions. Paper presented at the millennium drug awareness seminar on drug and its problems in Nigeria Tertiary Institution, Federal Polytechnic, Oko, Anambra State.

[3]. Adeniyi, K. E. (2016). Unemployment and drug trafficking among drug suspects in NDLEA custody, Cross River State Command, Nigeria. Unpublished M.Sc. Thesis submitted to the Department of Sociology, University of Calabar, Calabar.

[4]. Adeniyi, K. E. (2004). Drug laws in Nigeria. NDLEA perspective. Paper presented at NYSC orientation camp. Iyana-Ipaja, Lagos.

[5]. Bello, T. (2003). Attacking unemployment hurdles in the fragile economies of the sub-Saharan Africa: The experience of Nigeria. Paper presented at the - Economics for the future - Conference; On the occasion of the celebration of 100 years of Cambridge Economics; Cambridge, United Kingdom.

[6]. Dambazau, A. B. (2007). Criminology and criminal justice. Kaduna: Spectrum Books.

[7]. Ellis, S. (2009). West Africa's international drug trade. African Affairs, 108 (431), 171-196.

[8]. Felix, E. O. \& Ukwayi, J. K. (2014). Assessing the determinants of drug use and abuse among gender in a residential neighbourhoods of Calabar south local government area, Nigeria. Academic research international 5(4), 473-480

[9]. Fobur, Y. I. A (2009). Nigeria and the global drug war. Jos. Jos University Press Ltd.

[10]. Gadzama, S. (2010). Nigeria: Unemployment contributes to drug trafficking. Leadership Newspaper. Abuja

[11]. Godwin, A. (2007). Drug trafficking: An alarming human security threat. Accra, WARN policy brief

[12]. Idoko, I. F. (2013). The paradox of youths unemployment in an oil producing country: The lesson from the Nigerian experience. International Journal of Business and Management Invention, 4(2), 2319-8028.

[13]. Igbo, E. U. M. (2007). Introduction to criminology. Nsukka: Afro-Orbis Publication Ltd.

[14]. Iwarimie-Jaja D. (2012). Criminology: The study of crime. $4^{\text {th }}$ edition. Owerri; Spring-field publisher ltd.

[15]. Lafiaji, B. (2004). The drug quagmire: The way out. Publication of Public Affairs Unit, NDLEA, Lagos.

[16]. Maqbool, T. (2014). Drug trafficking: A non-traditional security threat to national security of Pakistan. Islamabad institute for strategic studies research and analysis. (ISSRA)

[17]. NDCMP (2015-2019). Response to drug and related organized crime in Nigeria. Lagos; National coordinating unit for the inter-ministerial committee on drug control NDLEA

[18]. Ndiyo, N. A. (2005). Fundamentals of research in behavioural sciences and humanities. Calabar: Wusen Press.

[19]. Okafor, E. E. (2011). Youth unemployment and implication for stability of democracy in Nigeria. Journal of Sustainable Development in Africa, 13(1), 1520-5509

[20]. Okoye, C. M. (1999). The impact of science and technology on Nigerian development. Journal of Science Education, 1 (6), 20-29.

[21]. Omadjohwofe, O. S. (2010). Drug prohibition and the problem of conformity. J. Psychology, 1(2), 91-97

[22]. Onifade, D. (2011). Power supply: We need the facts. The Guardian, Wednesday, 23 February.

[23]. Osgood, W. D., \& Chambers, J. M. (2000). Social disorganization outside the metropolis: An analysis of rural youth violence. Criminology, 5 (38), 81-116.

[24]. Oviawe, J. O (2010). Repositioning Nigeria youths for economic empowerment through entrepreneurship education. European Journal of Educational Studies, 2 (2), 113-118.

[25]. Schmitt, J., \& Warner, K. (2011). Ex-offenders and the labour market. Journal of Labour and Society, $14,87-109$.

[26]. Ugwuoke, C. U. (2010). Criminology: Explaining crime in the Nigerian context. Nsukka: Great Ap Express Publishers Ltd.

[27]. UNODC (2008). Drug trafficking is a security threat in West Africa

[28]. UNODC (2010). Human Development Report, New York: Oxford University Press.

[29]. USAID (2013). The development response to drug trafficking in Africa: A programme guide. USA. United State Agency for International Development. 